\title{
Commercialism and the Convergence of Alternative and Mainstream Media
}

\section{Linda Jean Kenix*}

University of Canterbury, New Zealand

Media scholarship has spent a great deal of time and energy exploring the differences between what have been labelled alternative and mainstream media. The research in this area has generally been thought provoking and has illustrated the importance of a diverse media system to democracy. However, future scholarship must question and investigate the complexities that now exist in categorizing and understanding our present media system within an omnipresent commercial ideology. While very important differences remain between generalized conceptions of alternative and mainstream media, the convergence of communicative technologies, coupled with changing economic mandates, commercialism, and a rising consumer culture, as well as a raft of other factors, have made the task of differentiating much mainstream and alternative media more problematic. These forces have continued to converge over recent years resulting in a far more homogenized spectrum of what has previously been conceptualized as distinctively mainstream and alternative media [1]. Future research must attempt to better understand what this convergence means for governments around the world, and if there are any potential avenues of interdependent growth that might continue to support democratic governmental systems.

The special features of OMICS Publishing and the Journal of Mass Communication \& Journalism create fertile ground for such research. An international and open access approach is needed if we are to understand the many influences that do exist on media content and the potentially unforeseen global consequences that these influences can have within instantaneously interconnected societies. Previous academic scholarship has argued that there is a hierarchy of influences [2] that coalesce to produce media content. This hierarchy is traditionally viewed visually as concentric circles, which first begin with individual motivations and gradually move 'outwards' through organizational practices, ownership models and finally ideology. All of these influences, except for ideology are largely at the level of production. This range of production processes, in varying degrees of strength and purpose, has been said to have a direct impact on what constitutes resulting media content. But what if ideology has become so pervasive that it overcomes all of the other levels of production? What if the content of alternative media is not as different from the mainstream as was once thought? Certainly, important points of demarcation continue to exist, but how would such signs of convergence complicate previous theories of a unique hierarchy of influences that has historically helped to describe mainstream media in counterpoint to the alternative press? Or are the hierarchies themselves conflated in today's technologically infused, commercial society? A broader, yet related, question is what does it mean to be alternative within a media spectrum that at least appears to include every taste, interest and political perspective possible?

These are the types of questions that the Journal of Mass Communication \& Journalism must attempt to answer as the content of media continues to overlap in focus, structure and reach. The possible reasons for this convergence of mainstream and alternative media are many. Technological advancements in communication have driven many of the changes in communication models. Citizens who now have access to social networking tools demand the same from their mainstream media, who, now under increasing financial constraints, are compelled to deliver. Also because of new technologies, some of the hierarchies of influence, particularly at the organizational level, have lost their importance. All media have become more disconnected with specific geographical spaces and organizational-specific mandates. The drive for commercial viability within an overarching ideology of consumerism and commercialism is an obvious driver of contemporary media practices. The mass dissemination of information through the Internet is also considered as a contributing reason for a confluence in content. Commercialism is frequently present as an ideological force in media content precisely because of the economic pressures within the modern media market. Research must recognize that the demands to increase revenue streams exist even within smaller, alternative media. The pervasiveness of commercialism within the ideology of our media, and of our lives, is difficult to measure, but these questions must be asked. Economic wealth has become not only a part of our media but also of our individual aspirations. Embedded within the ideology of commercialism is the drive to value profit over any notion of social responsibility or political engagement and this could have profound implications for democracies worldwide.

In a 2010 plenary presentation to the International Association for Media and Communication Research, the prominent media scholar Barbie Zelizer stated that 'media cultures can be defined as environments in which beliefs, actions, behaviours, values, mindsets and notions of authority, power and community come together with people, organizations and resources involved in some capacity with the media' [3]. This accurate and exhaustively inclusive definition of media problematizes any attempt to categorize media into coherent, contingent semantic divisions. Media extend into every facet of modern life, and information now duplicates in confounding multitudes. This struggle to capture the constitution of media itself is highlighted by the myriad of attempts at defining alternative media in academic scholarship. This is not to say that such attempts should not be undertaken. There is much to be learned from how media can be categorized along indices of industry, content, professions and approaches. However, there is

*Corresponding author: Linda Jean Kenix, University of Canterbury, New Zealand, Tel: +64 3364 2987; E-mail: lindajean.kenix@canterbury.ac.nz

Received January 10, 2012; Accepted January 10, 2012; Published January 12 2012

Citation: Kenix LJ (2012) Commercialism and the Convergence of Alternative and Mainstream Media. J Mass Communicat Journalism 2:e109. doi:10.4172/21657912.1000e109

Copyright: (c) 2012 Kenix LJ. This is an open-access article distributed under the terms of the Creative Commons Attribution License, which permits unrestricted use, distribution, and reproduction in any medium, provided the original author and source are credited. 
Citation: Kenix LJ (2012) Commercialism and the Convergence of Alternative and Mainstream Media. J Mass Communicat Journalism 2:e109. doi:10.4172/2165-7912.1000e109

Page 2 of 2

also much to be gained from a better understanding of the areas where such distinctions are blurred and categorizations are problematized.

\section{References}

1. Kenix LJ (2011) Alternative and mainstream media: The converging spectrum Bloomsbury Academic, London and New York.
2. Shoemaker PJ, Reese SD (1990) Mediating the message: Theories of influences on mass media content. Longman Publishing Group, New York.

3. Zelizer B (2010) Plenary Session: Building Accountable Media Cultures. In International Association for Media and Communication Research. Braga, Portugal. 